\title{
USULAN PERANCANGAN KABIN MASINIS KRL COMMUTER LINE YANG ERGONOMIS MENGGUNAKAN MODEL VIRTUAL ENVIROMENT
}

\author{
Djodi Erlangga $^{1}$, Nurfajriah ${ }^{2}$ \\ Program Studi Teknik Industri, Fakultas Teknik, Universitas Pembangunan Nasional "Veteran" \\ Jakarta \\ Jl. RS. Fatmawati No.1 Pondok Labu Jakarta Selatan \\ Email: djodierlangga@gmail.com, nurfajriah@upnvj.ac.id
}

\begin{abstract}
ABSTRAK
Ketidakergonomisan ruang kemudi Kereta Rel Listrik (KRL) dapat menyebabkan seorang masinis terkena Work Related Musculoskeletal Disorder (WMSDs) yang berdampak pada berkurangnya kemampuan konsentrasi saat mengoperasikan KRL yang cenderung statis. Penelitian dilakukan dengan tujuan untuk memberikan usulan desain ruangan kemudi terbaik, baik dari ukuran kursi dan kabin serta penempatan instrumen pengontrol dan layar pemantau yang dapat mengakomodasi postur kerja masinis agar terhindar dari WMSDs. Penelitian dilakukan dengan menganalisis risiko postur pengemudi dengan metode Quick Exposure Check (QEC) dan nilai Rapid Upper Limb Assessment (RULA) melalui pengujian Virtual Environment terhadap desain aktual dan desain usulan menggunakan konfigurasi Virtual Human Modelling dari data antropometri masinis yang telah diperoleh. Hasil yang terbaik merupakan desain yang memberikan nilai RULA terendah.
\end{abstract}

Kata kunci: Ergonomi, antropometri, quick exposure check, rapid upper limb assessment, model virtual environment

\begin{abstract}
Unergonomic working condition for driving cabin in commuter train (KRL) can cause a machinist to be exposed to work Related Musculoskeletal Disorders (WMSDs) which affects the diminished of concentration capabilities when operating KRL which tends to be static. This study aims to give the best design of steering room, both from chair and cabin size and the placement of the controller and monitor screen instrument that can accommodate the machinist work posture to avoid WMSDs. The research was conducted by analyzing the driver's posture using the Quick Exposure Check (QEC) method, and the value of Rapid Upper Limb Assessment (RULA) through Virtual Environment testing of the actual design and recommend design using the Virtual Human Modeling configuration from the anthropometric data of machinist that been obtained. The best result is the design that gives the lowest RULA value.
\end{abstract}

Ergonomic, anthropometry, quick exposure check, rapid upper limb assessment, virtual environment modelling.

\section{Pendahuluan}

Kenyamanan, keamanan, dan keselamatan penumpang merupakan prioritas utama yang terus ditingkatkan oleh PT. KCJ dalam upaya penyelenggaraan jasa transportasi kereta angkutan massal dalam kota yang berkualitas. PT. KCJ telah berhasil mengubah citra angkutan yang sebelumnya memiliki citra semerawut dengan melakukan berbagai revolusi seperti penambahan, penataan ulang, dan sterilisasi sarana dan prasarana termasuk jalur kereta dan stasiun kereta yang dilakukan bersama PT. KAI (Persero) dan pemerintah. Sayangnya perbaikan sarana dan prasarana fasilitas KRL Commuter Line untuk penumpang saat ini masih tidak beriringan dengan upaya perbaikan kenyamanan fasilitas untuk pegawai khususnya masinis yang berperan dalam mengoperasikan dan menjalankan KRL tersebut. Berbeda dengan pengoperasian kereta lokomotif antar kota yang desain kabin dan pengoperasian harus selalu didampingi oleh asisten masinis. Seorang masinis KRL Commuter Line dapat beroperasi sendirian dan juga dapat didampingi oleh asisten masinis tergantung rute, kedinasan, atau memberikan jam terbang kepada asisten masinis tersebut. Beberapa seri kabin KRL didesain dengan hanya satu kursi untuk masinis sehingga seorang asisten masinis harus berdiri atau membawa kursi tambahan saat mendampingi masinis. Kursi masinis dibuat sangat sederhana tanpa sandaran yang layak dengan tujuan agar dapat di lipat guna memudahkan teknisi untuk melakukan perawatan di ruang kabin. Selain itu di dalam kabin 
juga terdapat berbagai panel instrumen seperti tuas, tombol-tombol, dan display yang di tata cukup jauh untuk dijangkau seorang masinis dalam keadaan duduk. Hal tersebut membuat seorang masinis harus sering berdiri atau bersusah payah dalam menggapai panel instrument di dalam kabin KRL tersebut.

Sejumlah ilmuwan yakin bahwa bekerja dalam keadaan tegang dan waktu yang lama pada posisi yang tidak nyaman dan tidak wajar dapat mengundang risiko. Sikap kerja yang statis dalam jangka waktu yang lama lebih cepat menimbulkan keluhan pada sistem musculoskeletal $[1,2]$. Keluhan ini dirasakan pada bagian otot skletal yaitu meliputi otot leher, bahu, lengan, tangan, jari, punggung, pinggang, dan otot-otot bagian bawah. Postur duduk statis berpotensi menyebabkan terjadinya musculoskeletal disorders (MSD) hingga 50\% dengan risiko terbesarnya terjadi pada populasi dalam usia 20 hingga 45 tahun [3]. Selain itu, 80\% anggota tubuh masinis yang paling banyak mengalami keluhan adalah leher, punggung atas, lengan atas, bahu, punggung bawah, dan paha. Hal tersebut disebabkan oleh kurang sesuainya ukuran kursi dan desain kabin yang menyebabkan tubuh masinis membentuk postur duduk yang buruk hingga mengakibatkan cedera pada tubuh masinis [4].

Dalam mengendarai kereta listrik seorang masinis dituntut untuk selalu dalam kondisi prima dan tetap fokus terutama dalam membaca sinyal perkeretaapian baik secara visual dan pendengaran serta mempunyai motor skills yang baik dalam membuat keputusan yang mendesak. Oleh karena itu berbagai kondisi ketidaknyamanan pada masinis harus dapat dikurangi untuk menurunkan risiko yang dapat menyebabkan seorang masinis kehilangan fokus dan menyebabkan seorang masinis lalai dalam menjalankan pekerjaan sesuai dengan Standard Operation Procedure (SOP) dan berdampak pada keselamatan seluruh penumpangnya hingga sampai ketujuan.

Terlepas dari seorang masinis sudah berpengalaman atau belum, lingkungan kerja tetap perlu disesuaikan dengan kebutuhan. Penelitian ini bertujuan untuk melakukan evaluasi lingkungan kabin masinis KRL Commuter Line dengan penerapan kaidah ergonomi dengan menciptakan desain kabin masinis yang nyaman digunakan oleh penugasan masinis tunggal serta nyaman digunakan saat didamping oleh asisten masinis ataupun teknisi.

\section{Metode Penelitian}

Jenis penelitian menggunakan metode evaluasi dan pengembangan produk terhadap rancangan kabin KRL menggunakan kajian ergonomi sehingga masinis dapat mengoperasikan KRL dengan nyaman dan aman. Penelitian dilaksanakan di divisi Interior - Eksterior dan bagian KUPT Kru KA, Depo KRL Depok, PT KAI Commuter Line Jabodetabek yang berlokasi di Kelurahan Ratu Jaya, Kecamatan Pancoran Mas, Kota Depok, Jawa Barat. Observasi awal tiga dilaksanankan pada tanggal 03-31 Oktober 2016 dan pengambilan dan pelengkapan data di laksanakan pada tanggal 13, 19 April, dan 13 Mei 2017

\section{Metode Pengumpulan Data}

Data yang di kumpulkan dalam penelitian ini menggunakan jenis data kualitatif dan kuantitatif terkait interaksi antara masinis dan lingkungan kabin KRL Commuter Line seri JR East 205 yaitu data Exsposure Level yang dialami masinis saat mengendarai KRL dengan pengisian Quick Exposure Checklist Assessment oleh 60 sampel masinis/asisten masinis (metode slovin) dan pengamat, kemudian dilakukan pengukuran dimensi kabin KRL beserta panel instrumennya menggunakan meteran dan alat pengukur sudut, pengambilan gambar dan pengamatan postur kebiasaan masinis saat mengoperasikan KRL, dan pengukuran sampel dimensi tubuh (antropometri) masinis menggunakan anthropometer. Selain itu dilakukan pengumpulan studi litelatur dari berbagai sumber bacaan untuk menentukan rancangan kabin yang ergonomis.

\section{Metode Pengolahan Data}

Setelah data yang dikumpulkan mencukupi dilakukan pengolahan data antara lain sebagai berikut.

a) Pengolahan kuisioner QEC menggunakan aplikasi software Ergo Fellow 3.0 untuk mengetahui seberapa besar Exsposure Level dan tindakan yang harus dilakukan terhadap masinis KRL.

b) Pengolahan data antropometri masinis dengan pengujian keseragaman, kecukupan, normalitas, rata-rata dan standar deviasi sehingga didapat ukuran untuk menetukan ukuran-ukuran persentil antropometri yang akan di gunakan sebagai nilai konfigurasi desain usulan.

c) Membuat model desain aktual menggunakan software Autocad Mechanical 2015 berdasarkan pengamatan dan data ukuran kabin yang telah diperoleh.

d) Membuat model desian usulan menggunakan software Autocad Mechanical 2015 berdasarkan data persentil antropometri masinis dan studi literatur yang telah di kumpulkan.

e) Kemudian bentuk desain aktual dan usulan yang telah dibuat diterjemahkan ke dalam model virtual 
environment pada software Seimens Jack 8.4. Dalam software ini dibentuk model manusia (manikin) berdasarkan data antropometri masinis. Manikin kemudian diarahkan ke dalam bentuk postur mengemudi sesuai desain kabin aktual dan usulan. Dari postur manikin tersebut akan diperoleh output nilai RULA mengunakan Task Analysis (TAT) yang ada pada software untuk menilai kualitas ergonomi postur kerja yang dihasilkan dari tiap konfigurasi desain, pengulangan dan perbaikan rancangan desain usulan dapat dilakukan hingga akan diperoleh desain usulan yang paling ideal secara ergonomis.

\section{Hasil dan Pembahasan}

\section{Nilai Exposure level metode Quick Exposure Check (QEC)}

Hasil rekapitulasi pengolahan kuisioner QEC menggunakan software ergo fellow 3.0 terhadap 60 sampel masinis diidentifikasi bahwa level eksposur pada punggung diidentifikasi dalam rentan kategori sedang, bahu/lengan dalam rentan kategori sedang, pergelangan tangan/tangan dalam rentan kategori sedang dan leher terdapat 8 masinis dalam rentan kategori tinggi dan 52 masinis dalam kategori sangat tinggi.

Berdasarkan hasil perhitungan total skor akhir eksposur dan level tindakan yang diperoleh dari sampel yang bekerja ruang kemudi masinis masih beragam dan semua hasil level tindakan yang diperoleh menunjukkan 58 masinis mengalami eksposur level 3 dengan tindakan yang perlu dilakukan ialah tindakan dalam waktu dekat yang berarti tindakan perlu dilakukan secepatnya dan dua masinis mengalami eksposur level 4 dengan tindakan yang perlu dilakukan ialah diperlukan tindakan sekarang juga.

Adapun penyebab adanya perbedaan tingkat eksposur skor segmen tubuh dan total keseluruhan pada jenis pekerjaan yang sama (masinis) disebabkan oleh adanya penilaian persepsi individu seperti pertanyaan apakah masinis mengalami kesulitan dan apakah masinis mengalami stress saat mengemudikan KRL Commuter Line. Tindakan yang perlu dilakukan yakni memperbaiki postur kerja dengan cara merancang fasilitas kerja yang ergonomis bagi operator yaitu masinis. Agar masinis dapat merasakan kenyamanan dan keamanan dalam melakukan pekerjaannya sehingga dapat mengurangi bahkan menghilangkan risiko kerja akibat postur kerja yang tidak baik yang disebabkan oleh fasilitas kerja. Rancangan fasilitas kerja yang dibuat berupa perbaikan fasilitas ruang kemudi masinis KRL Commuter Line menggunakan metode ergonomi dan antropometri yang memerhatikan dimensi tubuh yang terkait dengan rancangan fasilitas kursi dan kabin.

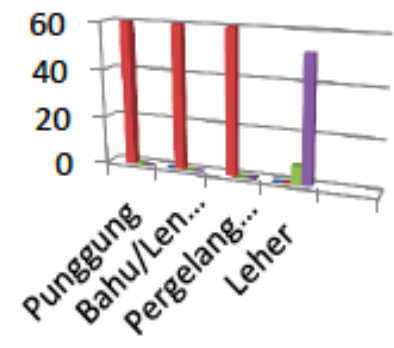

rendah

sedang

tinggi

sangat tinggi

Gambar 1. Exposure level segmen tubuh

Tabel 1. Data antropometri yang dikumpulkan

\begin{tabular}{clcclc}
\hline No & Dimensi Badan & Simbol & No & \multicolumn{1}{c}{ Dimensi Badan } & Simbol \\
\hline 1 & Tinggi Badan & TB & 12 & Lebar duduk & LD \\
2 & Berat badan & BB & 13 & Panjang siku ke jari & PSJ \\
3 & Tinggi mata & TM & 14 & Panjang pantat ke dengkul & PPD \\
4 & Tinggi mata duduk & TD & 15 & Pantat popliteal & P.Pop \\
5 & Tinggi duduk normal & TMD & 16 & Panjang telapak kaki & PTK \\
6 & Tinggi bahu duduk & TBD & 17 & Lebar telapak kai & LTK \\
7 & Tinggi siku duduk & TSD & 18 & Jangkauan tangan ke atas & JTA \\
8 & Tinggi popliteal & T.Pop & 19 & Jangkauan tang ke depan & JTD \\
9 & Tinggi lutut & TL & 20 & Rentang siku ke siku & RSS \\
10 & Lebar bahu & LB & 21 & Rentang tangan & RT \\
11 & Lebar siku & LS & & & \\
\hline
\end{tabular}

Sumber : Penulis 


\section{Rancangan Desain}

\section{Desain Aktual}

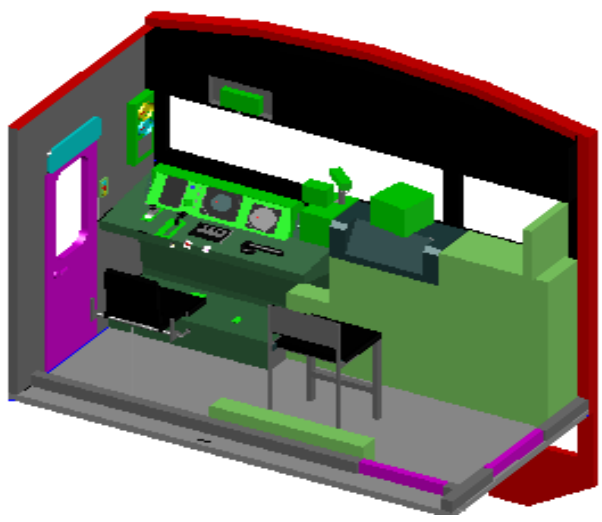

Gambar 2. Desain aktual

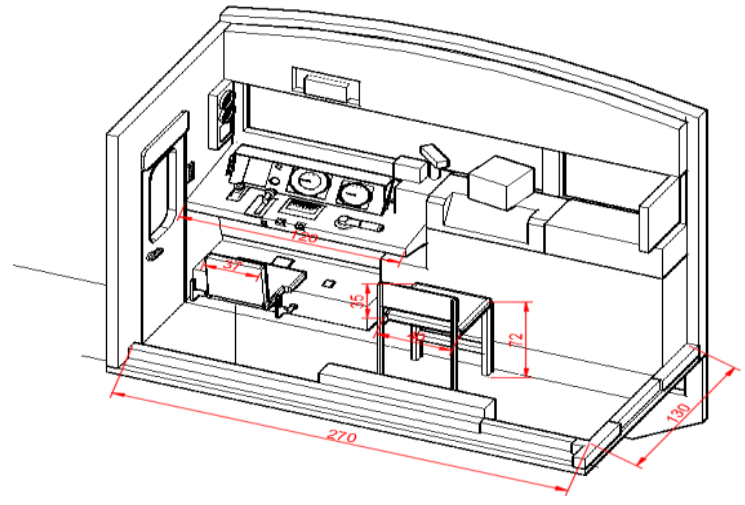

(a)

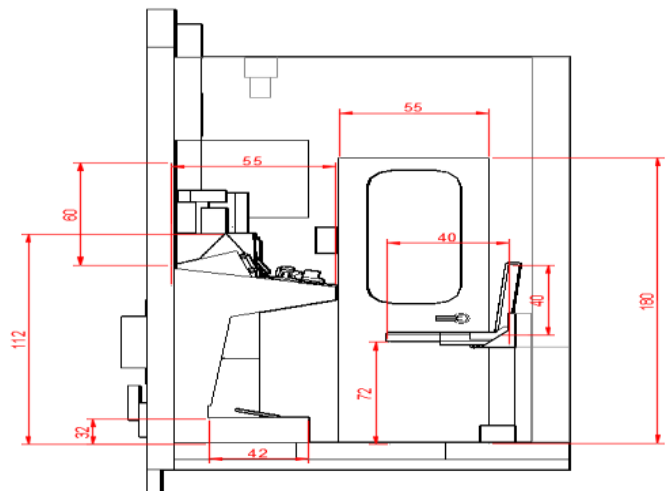

(b)

Gambar 3. (a). Ukuran desain aktual (SW isometris), (b). Ukuran desain aktual tampak samping

Dimensi ukuran ruang kemudi masinis aktual adalah sebagai berikut.

1. Ruang masinis

2. Pintu

3. Kaca depan

4. Kursi masinis

- Dudukan

- Tinggi dudukan

- Sandaran

- Jarak kursi ke kabin

5. Kursi asisten masinis

- Dudukan

- Tinggi dudukan

- Sandaran

- Bantalan sandaran

6. Alas pijakan

7. Deatman pedal

8. Pedal lampu sinyal

9. Kabin kemudi

10. Kemiringan primary control

11. Kemiringan primary display

12. Tinggi emergency brake
: $270 \times 140 \times 230 \mathrm{~cm}$

: $180 \times 55$ x $5 \mathrm{~cm}$ (3 unit)

: $260 \times 55 \mathrm{~cm}$, kemiringan $90^{\circ}$

: $40 \times 33 \times 5 \mathrm{~cm}$

: $72 \mathrm{~cm}$

: $40 \times 37 \times 5 \mathrm{~cm}$, kemiringan $100^{\circ}$

: $25 \mathrm{~cm}$

: $35 \times 40 \times 5 \mathrm{~cm}$

$: 72 \mathrm{~cm}$

: 37 x 37 x $5 \mathrm{~cm}$, kemiringan $120^{\circ}$

: $31 \times 25 \mathrm{~cm}$

: $90 \times 42 \times 32$

: $26 \times 9 \times 1 \mathrm{~cm}$, kemiringan $15^{\circ}$

: $5 \times 4 \times 1 \mathrm{~cm}$, kemiringan $15^{\circ}$

: 120 x 55 x $112 \mathrm{~cm}$

$: 10^{\circ}$

$: 110^{\circ}$

: $240 \mathrm{~cm}$ 


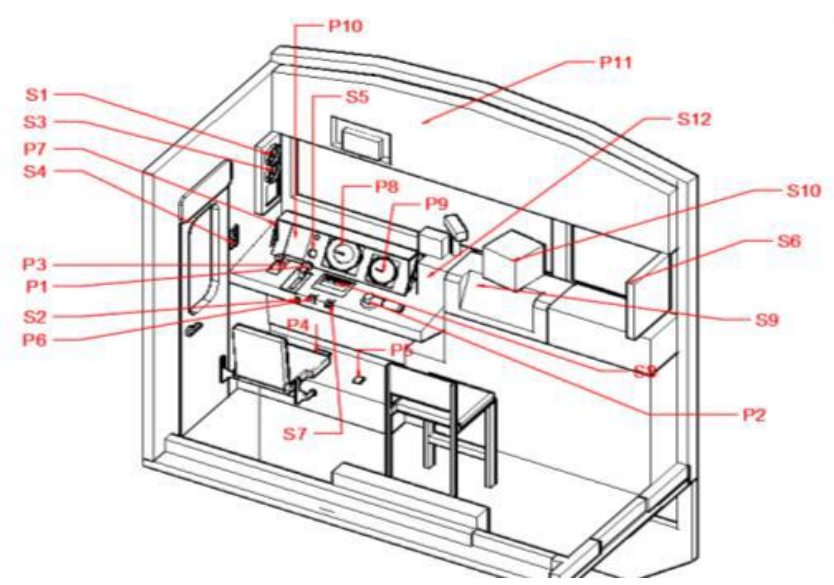

Gambar 4. Instrumen kontrol desain

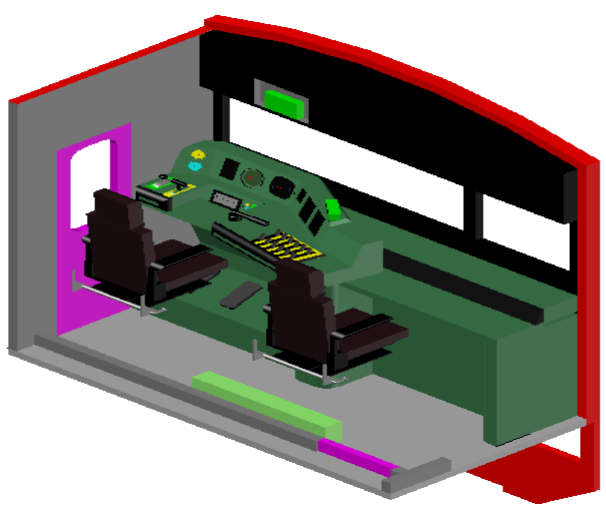

Gambar 5. Desain usulan

Tabel 2. Keterangan kendali kontrol

\begin{tabular}{cccc}
\hline Kode & Dimensi Badan & Kode & Dimensi Badan \\
\hline P1 & Tuas kecepatan & S2 & Tuppercuren \\
P2 & Tuas rem & S3 & Tegangan batre \\
P3 & Reverser & S4 & Power panthograf \\
P4 & Deatman pedal & S5 & Switch kepala KRL \\
P5 & Pedal lampu & S6 & Pengatur suhu \\
P6 & Sinyal & S7 & Tombol pintu \\
P7 & Suling/klakson & S8 & Lampu jalan \\
P8 & Speedometer & S9 & Tombol-tombol lampu dan AC \\
P9 & Daya tegangan & S10 & Display suhu \& tegangan udara \\
P10 & Layar fungsi & S11 & Layar pemantau CCTV \\
P11 & Emergency brake & S12 & Indicator Rute \\
S1 & Manometer & & \\
\hline
\end{tabular}

Sumber: Pengumpulan data

\section{Desain Usulan}

Perancangan tempat duduk dibuat mengikuti prasyarat tempat duduk masinis di Peraturan Menteri Perhubungan KM 40 pasal 15 ayat 2 yaitu "Tempat duduk M/AM sebagaimana ayat 1a, harus ergonomis dengan diberi sandaran, dapat diatur maju mundur, naik turun, dan berputar". Oleh sebab itu kursi diusulkan ajustable yang dapat di atur posisi ketinggian, posisi maju-mundur, dan dapat sedikit berputar $30^{\circ}$ ke kiri dan ke kanan dengan pengunci untuk mendukung pergerakan masinis dalam menggunakan instrumen pengendali utama dan pendukung usulan tanpa harus mengubah posisi tubuh untuk menghindari perubahan postur tubuh yang berisiko terkena WMSDs. Kursi dibuat fullseat dengan sandaran punggung penuh, sandaran tangan yang dapat dilipat, dan sandaran kepala untuk meningkatkan tingkat kenyamanan masinis. 


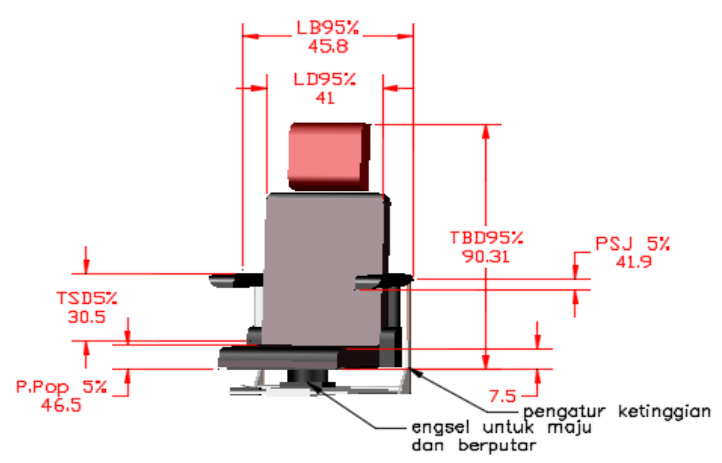

Gambar 6. Kursi desain usulan (Sumber: Hasil rancangan)

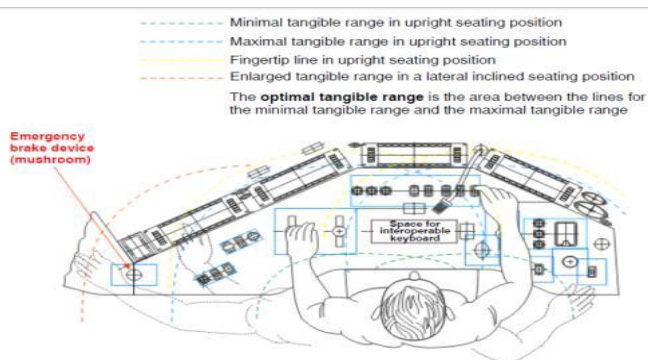

Gambar 7. Penempatan area jangkauan kontrol metode tangiable range according menurut International Union Railway [5]

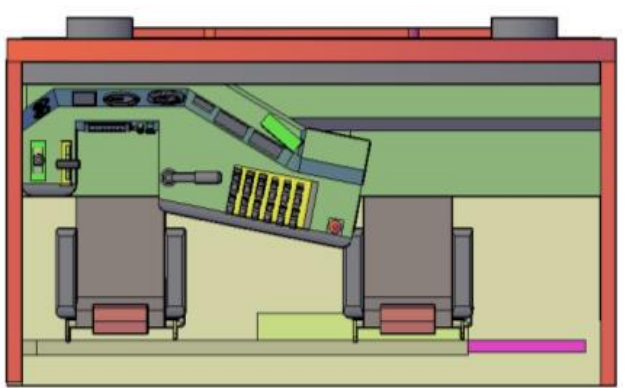

(a)

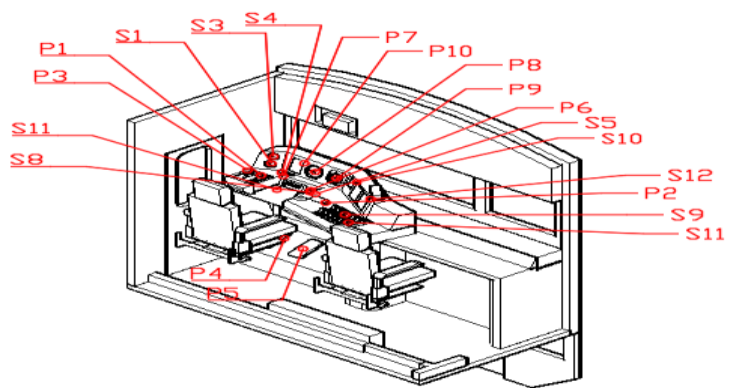

(b)

Gambar 8. (a) Model kendali rancangan usulan dan (b) instrumen kontrol desain usulan (Sumber: Hasil rancangan

Ukuran dimensi kursi adalah sebagai berikut.

Dudukan

: LD $95 \%$ x P.Pop $5 \%$ x $7,5 \mathrm{~cm}$

: $41 \times 46,5 \times 7,5 \mathrm{~cm}$

Sandaran $\quad:$ LD $95 \% \times 7,5 \times$ TBD $95 \%, 95^{\circ}-120^{\circ}$

Tinggi Dudukan : tinggi alas kaki + T.Pop 5\% - 95\%

$: 32+44$ s.d $46=76-78 \mathrm{~cm}$ (adjutsable)

Peracangan kabin kendali dan tata letak instrumen penempatan Primary Control and Display di depan masinis, dan penempatan Secondary Control and Display di sisi kiri dan kanan Primary Control and Display. Penempatan tersebut dibuat tidak jauh dari jangkauan tangan masinis dengan desain sedikit melengkung mengitari bagian depan badan masinis. Penempatan seperti ini dapat dikatakan cukup ergonomis karena dapat mengoptimalkan daya jangkau (tangible range according) masinis dalam menggunakan alat kendali utama dan pembantu sehingga masinis dapat mengoperasikan kereta seorang diri tanpa kesulitan.

Ukuran pedal deatman dan pedal lampu disamakan dengan ukuran persentil 95\% panjang dan lebar telapak kaki yaitu 31,35 x $15 \mathrm{~cm}$ dengan sudut kemiringan $30^{\circ}$, sedangkan ketinggian alas kaki tetap mengikuti desain aktual yaitu $32 \mathrm{~cm}$. 


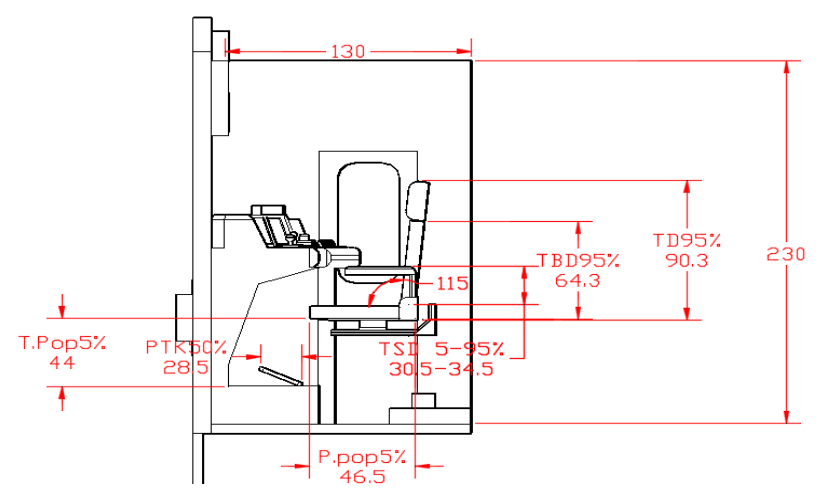

Gambar 10. Ukuran desain usulan tampak samping (Sumber: Hasil rancangan)

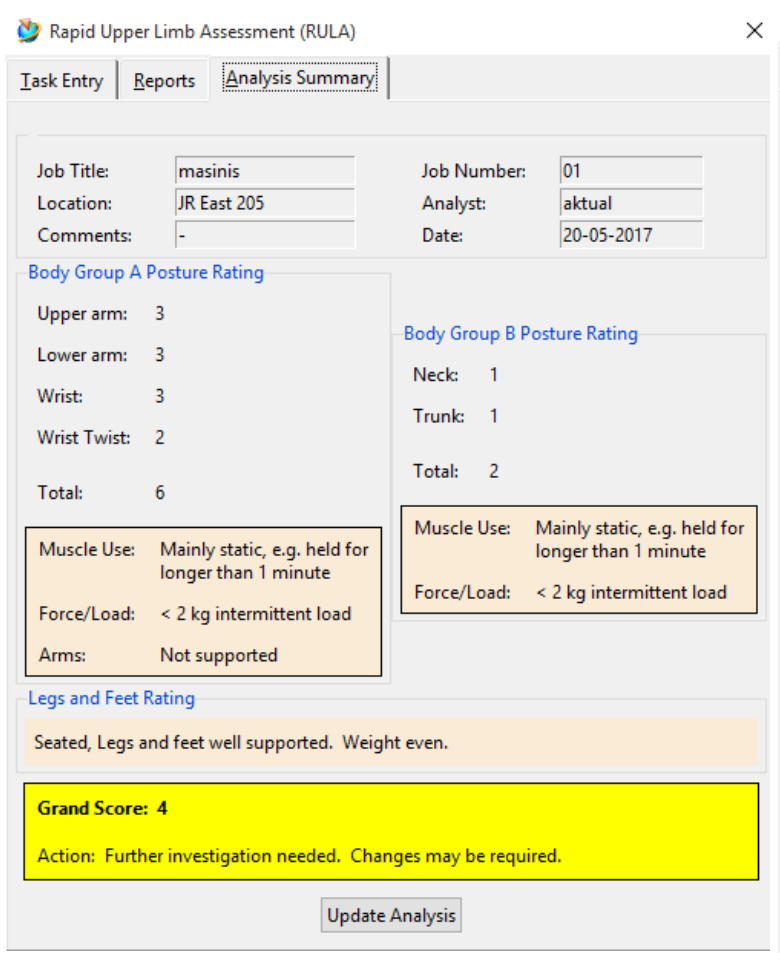

(a)

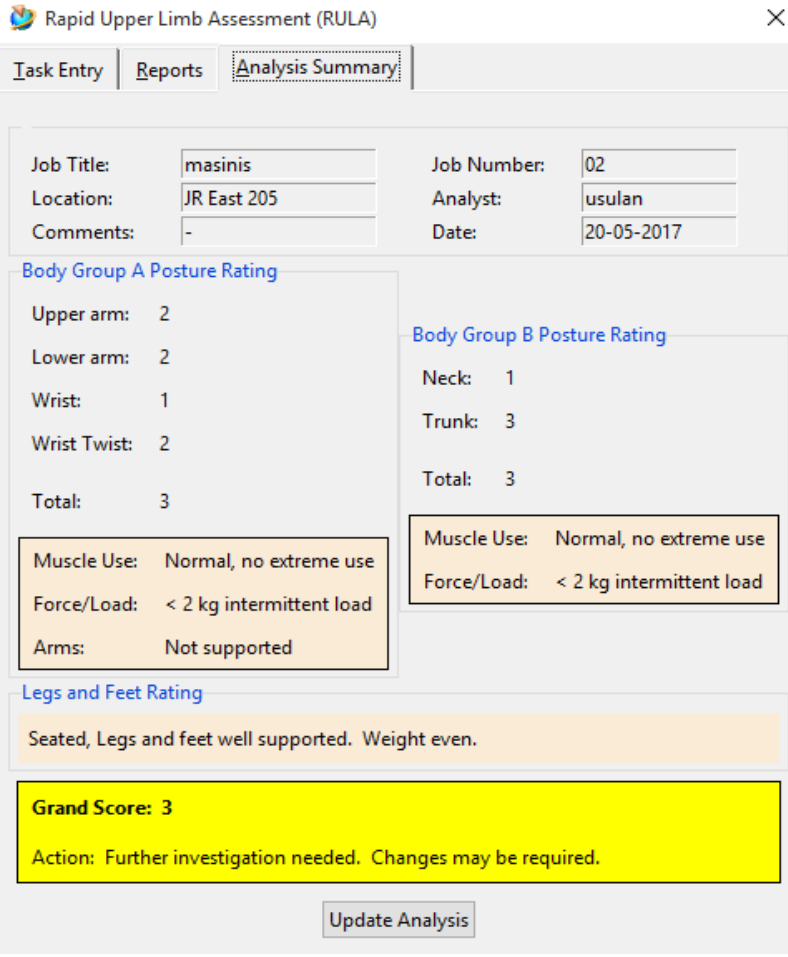

(b)

Gambar 11. (a) Grand score RULA desain actual dan (b) grand score RULA desain usulan (Sumber: Output TAT Software Jack 8.4)

\section{Nilai Rula pada Virtual Enviroment}

Grand score yang didapat pada desain aktual bernilai 4 artinya risiko WMSDs berada pada tingkat sedang dan butuh perbaikan dimasa yang akan datang. Pada desain aktual kelompok A menghasilkan nilai masing-masing 3 untuk lengan atas, 3 untuk lengan bawah, 3 untuk pergelangan tangan dan 2 untuk perputaran pergelangan tangan. Hal ini mengindikasikan bahwa posisi lengan atas harus segera diperbaiki karena pada postur duduk ini. Lengan atas masinis mengangkat dengan cukup tinggi dan memiliki posisi kedepan dalam interval 45 hingga 90 derajat untuk meraih tuas kendali yang berada didepannya. Perputaran pergelangan tangan yang memiliki nilai sebesar 2 mengindikasikan bahwa pergelangan tangan sedikit mengalami perputaran. Sedangkan untuk kelompok bagian tubuh B, nilai yang diperoleh adalah 1 untuk leher dan 1 untuk batang tubuh yang menunjukan postur dalam keadaan normal.

Grand score yang didapat pada desain usulan bernilai 3 yang artinya desain usulan juga masih memungkinkan terkena risiko WMSDs berada pada tingkat sedang dan butuh perbaikan di masa yang akan datang. Pada desain usulan kelompok A menghasilkan nilai masing-masing 2 untuk lengan atas, 2 untuk lengan bawah, 1 untuk pergelangan tangan dan 2 untuk perputaran pergelangan tangan. Hal ini mengindikasikan lengan atas masinis 
mengangkat posisi kedepan dalam interval 20 hingga 45 derajat untuk meraih tuas kendali yang berada di depannya. Perputaran pergelangan tangan yang memiliki nilai sebesar 1 mengindikasikan bahwa pergelangan tangan tidak mengalami perputaran dan berada pada kondisi normal, tidak membengkok. Sedangkan untuk kelompok bagian tubuh $\mathrm{B}$, nilai yang diperoleh adalah 1 untuk leher dan 3 untuk batang tubuh. yang menunjukan postur batang tubuh harus segera di perbaiki karena terlalu mennyandar ke sandaran kursi.

\section{Kesimpulan}

1) Dengan metode QEC diperoleh total skor exsposure level yang dialami masinis saat mengoperasikan KRL Commuter Line ada pada rentan $62-69 \%$ atau berada pada level 3 yaitu termasuk tinggi. Tingkat eksposur pada segmen tubuh punggung, bahu, tangan, dan leher ada pada kategori sedang, sehingga diperlukan tindakan perbaikan perlu dilakukan secepatnya.

2) Hasil analisis terhadap ukuran dimensi aktual yang digunakan pada KRL JR East 205 melalui hasil pengamatan dan pengujian dengan menggunakan virtual enviroment menunjukkan bahwa ukuran kursi yang digunakan saat ini kurang sesuai dengan ukuran tubuh masinis. Desain kursi yang menempel pada dinding dan cukup sederhana menyebabkan kursi terlalu jauh dengan kabin tuas pengendali. Selain itu penempatan instrumen pengontrol dan pemantau pendukung di nilai kurang ergonomis karena di letakan terlalu jauh dari jangkauan dan penglihatan masinis sehingga masinis harus mengubah mengubah postur duduk dan penglihatan untuk menjangkau instrumen tersebut.

3) Desain yang diusulkan dengan mempertimbangkan ukuran ruangan yang cukup sempit dengan mempertimbangkan tingkat prioritas dan keharmonian instrumen pengendali menggunakan metode tangle according atau kemampuan jangkauan tangan.

4) Nilai grand score pada pengujian desain aktual menggunakan RULA adalah 4. Hal ini menunjukan bahwa dampak risiko WMSDs pada desain aktual berada pada tingkat sedang, dan butuh perbaikan segera. Sedangkan grand score pada pengujian desain usulan menggunakan RULA adalah 3. Hal ini menunjukan bahwa dampak risiko WMSDs pada desain usulan berada pada tingkat sedang namun lebih baik dari desain aktual.

5) Desain aktual dan desain usulan pada rancangan kabin masinis KRL JR East 205 memiliki nilai grand score yaitu 4 dan 3 artinya kedua desain sama-sama memiliki risiko WMSDs dalam kategori sedang. Akan tetapi, pada rancangan kabin usulan sudah dilakukan perbaikan kenyamanan seperti penyesuaian ukuran tubuh masinis, perbaikan kursi menjadi fullset (mempunyai sandaran punggung, kepala, dan lengan) dan ajustable untuk penyesuaian posisi kenyamanan masinis yang berbed-beda, namun tetap dapat di lipat untuk menghemat ruang. Desain kabin di ubah dengan konsep tangle range according yang membuat penempatan primary dan secondary control-display berada dalam jangkauan masinis sehingga masinis dapat mengendarai KRL.

\section{Referensi}

[1] E. Garandjean, Fitting the task to the man: A textbook of occupational ergonomics, 4th edition. London: Taylor \& Francis, April 1988.

[2] S. Pheasant, Ergonomics, work and health. London: Macmillan academic and profesional LTD, 1991.

[3] A. Hedge, Anthropometry and workspace design. New York: Cornell University, 2009.

[4] C. P. Paramita, "Perancangan kursi masinis yang ergonomis pada KRL commuter Jabodetabek dengan menggunakan human modeling, Skripsi Teknik Industri Universitas Indonesia," 2012, tidak dipublikasikan.

[5] UIC Code 2009, Driver machine interfaces for EMU/DMU, locomotives and driving coaches - functional and system requirements assiciated with harmonised driver machine interfaces, 1st editon, German. International Union of Railway, 2009. 